\title{
Reliability of self reported form of female genital mutilation and WHO classification: cross sectional study
}

\author{
Susan Elmusharaf, Nagla Elhadi, Lars Almroth
}

\begin{abstract}
Objective To assess the reliability of self reported form of female genital mutilation (FGM) and to compare the extent of cutting verified by clinical examination with the corresponding World Health Organization classification.

Design Cross sectional study.

Settings One paediatric hospital and one gynaecological outpatient clinic in Khartoum, Sudan, 2003-4.

Participants 255 girls aged 4-9 and 282 women aged 17-35.

Main outcome measures The women's reports of FGMthe actual anatomical extent of the mutilation, and the corresponding types according to the WHO classification. Results All girls and women reported to have undergone FGM had this verified by genital inspection. None of those who said they had not undergone FGM were found to have it. Many said to have undergone "sunna circumcision" (excision of prepuce and part or all of clitoris, equivalent to WHO type I) had a form of FGM extending beyond the clitoris (10/23 (43\%) girls and $20 / 35$ (57\%) women). Of those who said they had undergone this form, nine girls (39\%) and 19 women (54\%) actually had WHO type III (infibulation and excision of part or all of external genitalia). The anatomical extent of forms classified as WHO type III varies widely. In 12/32 girls (38\%) and 27/245 women (11\%) classified as having WHO type III, the labia majora were not involved. Thus there is a substantial overlap, in an anatomical sense, between WHO types II and III.

Conclusion The reliability of reported form of FGM is low. There is considerable under-reporting of the extent. The WHO classification fails to relate the defined forms to the severity of the operation. It is important to be aware of these aspects in the conduct and interpretation of epidemiological and clinical studies. WHO should revise its classification.
\end{abstract}

\section{Introduction}

Despite many decades of campaigns and legislation, female genital mutilation (FGM) is still highly prevalent in the areas where it has traditionally been practised and is still practised in girls from these areas now living in Europe. FGM comprises any procedure where parts of the female genitals are removed without medical indication. The practice is also known as female genital cutting or female circumcision. It is practised in 27 countries in Africa, mainly in northeast Africa and in a belt reaching from east to west north of the equator. ${ }^{1}$ About $90 \%$ of women in northern Sudan have undergone FGM. ${ }^{23}$ The practice is also seen in the Middle East (parts of Oman, the United Arab Emirates, and Yemen) and in other countries such as Indonesia and Malaysia. ${ }^{45}$ Even though many people re-evaluate and abandon the practice when they emigrate, ${ }^{6}$ there is evidence that it continues in Europe. ${ }^{7-9}$ Many Somali girls living in London have been subjected to genital mutilation after moving from their home country. ${ }^{10}$ In the United Kingdom, though data on prevalence are scarce, there are thought to be 3000-4000 new cases every year. ${ }^{11}$

The World Health Organization has classified the forms of cutting into four types (table 1). ${ }^{12}$ Many communities use local terms for the practice. Type I is traditionally most often referred to as "sunna." The most severe form, infibulation and excision, or WHO type III, is also known as "pharaonic circumcision" in Sudan and "Sudanese circumcision" in Egypt. ${ }^{12}{ }^{13}$ A modified, less extensive form of infibulation has been called "intermediate circumcision," ${ }^{1415}$ "type II," ${ }^{16}$ or "matwasat" in Sudan. ${ }^{216}$ "Excision" is another term sometimes mentioned. ${ }^{13}{ }^{15} 17-19$ This could correspond to either WHO type I or II, depending on whether only the clitoris is removed or the labia minora as well.

Almost all studies about the prevalence and trends of FGM are based on women's reports. It is not known how this reported form corresponds to reality. The validity of reported forms of FGM, and what the local terms correspond to in anatomical terms, is an important issue that should be considered in the interpretation of studies based on interviews. We used clinical examination to assess the reliability of self reported form of FGM in Sudan and compared these reports with the extent of cutting verified by clinical examination; we also compared it with the corresponding WHO classification.

\section{Methods}

Data were obtained from two different hospital based studies in Khartoum, the methods of which have been described elsewhere. ${ }^{2021}$ We interviewed women recruited for a casecontrol study looking into primary infertility as a consequence of genital mutilation in childhood ${ }^{21}$ for information about their form of FGM. Cases were women aged $\leq 35$ with primary infertility. The study included 102 women with unknown causes of infertility and whose partners were fertile. Controls were women aged $\leq 35$ who were having their first baby and had no history of

Table 1 WHO classification of female genital mutilation ${ }^{12}$

\begin{tabular}{ll} 
Type & \multicolumn{1}{c}{ Detail } \\
\hline II & Excision of prepuce and part or all of clitoris \\
\hline III & $\begin{array}{l}\text { Excision of prepuce and clitoris together with partial or total excision of labia } \\
\text { minora }\end{array}$ \\
\hline IV & $\begin{array}{l}\text { Infibulation and excision of part or all of external genitalia } \\
\text { clitoris and or labia }\end{array}$ \\
\hline
\end{tabular}


infertility $(n=180)$. Pregnant women were the healthiest women coming to hospital who could be used as a control group and in whom we could justify the need for genital examination and were used as a proxy for the normal population. The study took place at Khartoum Teaching Hospital and Soba University Hospital from March 2003 to June 2004.

Girls were recruited as part of another study looking into paediatric complications of genital mutilation with special reference to urogenital symptoms, signs, and diagnoses in a public hospital emergency ward in Khartoum, Sudan. ${ }^{20}$ We consecutively recruited girls aged $4-9(n=255)$ who presented to the emergency ward and obtained demographic data and a detailed history. The guardians of the girls were asked whether the girls had undergone FGM.

For both groups, those who reported having undergone genital mutilation were then asked at what age and what form of FGM had been done. After obtaining informed consent from the woman or guardian, the doctor conducted a full physical examination, including genital inspection, to verify the exact anatomical extent of the operation. For the girls, the examination was performed by female paediatricians in a secluded room to guarantee privacy. The women were examined by gynaecologists in the gynaecological outpatient clinic. All doctors had received special training so they classified FGM in the same way. Particular efforts were made to avoid observer bias concerning the extent of vulval damage. Doctors were given detailed instructions on how to visualise and describe the extent of anatomical excision seen in each patient (to describe whether the clitoris, labia minora, and labia majora, respectively, were untouched, partially removed, or totally removed and whether the sides were stitched and at what level).

All the women and the guardians of girls included in the study gave their informed consent and the girls their informed assent.

\section{Statistical methods}

We used the Mann-Whitney test to analyse continuous variables and $\chi^{2}$ to test for differences between proportions, with $\mathrm{P}<0.05$ indicating significance unless otherwise stated.

\section{Results}

Altogether we included 537 participants in the study: 255 girls aged 4-9and 282 women aged 17-35. Of these, 52 girls and 275 women had undergone FGM. We had no data on the anatomical extent of FGM (clinical inspection of genitals) for two women and four girls. For one girl and one woman information was

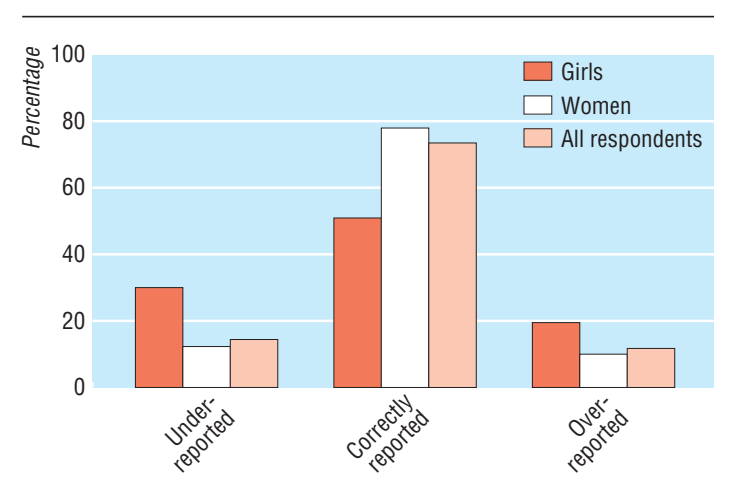

Proportion of girls and women who under-reported, correctly reported, and over-reported their form of FGM

missing on reported form. Ten women did not know their form of FGM.

Genital inspection verified FGM in all women and girls reported to have undergone the procedure. Correspondingly, none of those who said they did not have any form of FGM were found to have it

Tables 2 and 3 show the anatomical features of the different traditional terms used to describe forms of FGM and the WHO classification, respectively. Many who said they had undergone "sunna" (which should correspond to WHO type I) had a form of FGM extending beyond the clitoris (20/35 (57\%) women and $10 / 23$ (43\%) girls). Nineteen (54\%) women and nine (39\%) girls reported to have undergone "sunna" actually had WHO type III (infibulation and excision of part or all of external genitalia). Out of those who reported that they had undergone the "intermediate" form, 14 (82\%) women and four (80\%) girls had WHO type III, as classified by the doctor on inspection. The figure shows the proportions of girls and women who under-reported, correctly reported, and over-reported their form of FGM. It shows that the form of FGM is reported incorrectly in one in four respondents. Out of the 10 women who did not know their form of FGM, seven had type III.

The anatomical extent of forms classified as WHO type III varied widely (table 3$)$. In 27 (11\%) women and 12 (38\%) girls classified as having WHO type III, the labia minora were stitched but the labia majora were not involved. Thus there is a substantial overlap, in an anatomical sense, between WHO types II and III.

We carried out further analysis to check for the possible influence of other factors on the results. When those women

Table 2 Correlation between anatomical extent of FGM and reported form in 47 girls and 262 women* who had reported a form of circumcision and had genital inspection done

\begin{tabular}{|c|c|c|c|c|c|c|}
\hline \multirow{3}{*}{ Anatomical extent of genital mutilation } & \multicolumn{6}{|c|}{ Reported form of genital mutilation } \\
\hline & \multicolumn{2}{|c|}{ Sunna } & \multicolumn{2}{|c|}{ Intermediate } & \multicolumn{2}{|c|}{ Pharaonic } \\
\hline & Girls & Women & Girls & Women & Girls & Women \\
\hline Prepuce only & $-\dagger$ & $-\dagger$ & $-\ddagger$ & - & $-\ddagger$ & - \\
\hline Part or whole clitoris & $13 \dagger$ & $15 \dagger$ & - & $2 \ddagger$ & - & $1 \neq$ \\
\hline Clitoris + labia minora without stitching & $1 \S$ & $1 \S$ & $1 \dagger$ & $-\dagger$ & $1 \neq$ & $1 \neq$ \\
\hline Clitoris + labia minora with stitching & $5 \S$ & $7 \S$ & $-\dagger$ & $3 \dagger$ & $7 \ddagger$ & $16 \ddagger$ \\
\hline Clitoris + labia majora without stitching & $-\S$ & $-\S$ & $-\S$ & $-\S$ & $1 \ddagger$ & $6 \ddagger$ \\
\hline Clitoris + labia majora with stitching & $4 \S$ & $12 \S$ & $4 \S$ & $11 \S$ & $10 \dagger$ & $187 \dagger$ \\
\hline
\end{tabular}

Sunna should correspond to WHO type I; pharaonic should correspond to WHO type III.

*Information missing on reported form for one girl and one woman; 10 women did not know their form of FGM; data missing on anatomical extent of FGM (clinical inspection of genitals) for two women and four girls.

tExpected extent of operation.

$\ddagger$ ver-reporting of extent of FGM.

§Under-reporting of extent of FGM. 
Table 3 Actual anatomical extent of different forms of FGM, as classified by WHO type

\begin{tabular}{|c|c|c|c|c|c|c|}
\hline \multirow{2}{*}{ Anatomical extent of genital mutilation } & \multicolumn{2}{|c|}{ Type I } & \multicolumn{2}{|c|}{ Type II } & \multicolumn{2}{|c|}{ Type III } \\
\hline & Girls & Women & Girls & Women & Girls & Women \\
\hline Prepuce only & - & - & - & - & - & - \\
\hline Part or whole of clitoris & 13 & 19 & - & - & - & - \\
\hline Clitoris + labia minora without stitching & - & - & 3 & 2 & - & - \\
\hline Clitoris + labia minora with stitching & - & - & - & - & 12 & 27 \\
\hline Clitoris + labia majora without stitching & - & - & - & 7 & $1^{*}$ & $5^{\star}$ \\
\hline Clitoris + labia majora with stitching & - & - & - & - & 19 & 213 \\
\hline
\end{tabular}

${ }^{*}$ The girl and the five women classified as type III had labia minora stitched; the labia majora were cut but not stitched.

who reported their form correctly were compared with those who did not, the two groups did not differ regarding age (median 25 for both, $\mathrm{P}=0.8$ ), years in school (median 12 for both, $\mathrm{P}=0.18$ ), or years since the procedure was performed (median 19 and 18 , respectively, $\mathrm{P}=0.87$ ). Comparison of guardians who reported the correct form of FGM in their girls with those who did not also showed that the two groups did not differ regarding age (median 29 and 30.5 , respectively, $\mathrm{P}=0.45$ ) and years in school (median 1 and 2, respectively, $\mathrm{P}=0.99$ ), but for those who reported the form correctly the time elapsed between the procedure and the observation was shorter (median 1 and 3 years, respectively, $\mathrm{P}=0.002$ ).

Table 4 shows how the distribution of forms of FGM varied in the study population, depending on what classification is used.

\section{Discussion}

The reliability of reported form of FGM is low, and the WHO classification fails to relate the defined forms to the severity of the operation. It is important to be aware of these aspects in the design and interpretation of epidemiological and clinical studies on this topic.

\section{Strengths and limitations}

There are a few methodological limitations with our study. As a hospital based study, it was not designed to obtain a representative sample of girls and women in the area, though our observed prevalence among women was similar to that seen in the last community based survey $(97 \%$ and $91 \%))^{2}$ The study was, however, accurately designed for the objectives of the study. To avoid observation bias all the doctors who performed genital inspection received special training on how to classify and assess the extent of genital cutting. There was no blinding of the observer-that is, the doctors who examined the women and girls and classified the form of FGM knew what form the women or guardians had reported. To obtain an accurate classification, the doctors described in anatomical terms what had been removed and stitched and classified the type afterwards on the basis of the records.

Recall bias in the women and guardians might have affected the results. Many factors contribute to recall bias, not least psychological aspects, and it is not possible to control for most of them. Time elapsed between the procedure and the observation could be relevant. For adult women there was no difference in this time period between those who reported correctly and incorrectly, but for girls there was. It is difficult to explain this difference, but it probably has more to do with a tendency to justify what has been done by using the religious term "sunna" than the time passed. In the past few years there has been an intense debate in Sudan on the legal and religious status of "sunna circumcision." This has given FGM a religious context, which traditionally it did not have.

\section{Reliability of reported form of FGM}

There was complete agreement between reporting having undergone FGM or not and what was found by inspection of genitals, in both girls and women. In this regard our findings differ from previous studies. In urban and rural Tanzania there was inconsistency between self reported and clinically determined FGM in more than $20 \%$ of women (women tended to say they had not undergone FGM when they had). ${ }^{22}{ }^{23}$ These studies investigated the reporting of having undergone FGM or not and did not comment on the reliability of reporting of different forms. A study from Nigeria showed that self reporting was reliable in $79 \%$ of women. ${ }^{24}$ In this study most women were unsure of what had actually been done, so the authors could not investigate the validity of reporting by type. In rural Gambia a community based study showed $97 \%$ agreement between reported status of FGM and what was found on examination. Among those who reported incorrectly, in more than half who reported having undergone the procedure examination found no evidence of FGM, and in a quarter there was under-reporting of the extent of FGM. $^{25}$

To our knowledge there are no previous studies examining the reliability of the reported specific form of FGM compared with what is found on clinical examination. Our study shows that the self reporting of different forms of FGM is not reliable. This should be considered in the interpretation of studies based on interviews showing a change in practice towards less severe forms. ${ }^{26} 27$ There could be other reasons for reporting milder forms, rather than a change in practice per se.

Our results indicate an extensive over-reporting of the "sunna" form. The word "sunna" refers to what the prophet Muhammed has said or done. By using the term "sunna" the practice is associated with Islam and given a religious value. Thus, one possible reason for the widespread under-reporting of

Table 4 Distribution of forms of FGM according to different classification systems. Figures are numbers (percentage) of women or girls*

\begin{tabular}{|c|c|c|c|c|c|c|c|c|c|}
\hline & \multicolumn{3}{|c|}{ WHO classification $(n=321) \dagger$} & \multicolumn{3}{|c|}{ Reported form $(\mathrm{n}=315) \ddagger$} & \multicolumn{3}{|c|}{ Extent of mutilation $(\mathrm{n}=321) \dagger$} \\
\hline & Type I & Type II & Type III & Sunna & Intermediate & Pharaonic & Clitoris & Labia minora & Labia majora \\
\hline Girls aged 4-9 & $13(27)$ & $3(6)$ & $32(67)$ & $27(53)$ & $5(10)$ & $19(37)$ & $13(27)$ & $15(31)$ & $20(42)$ \\
\hline Women aged 17-35 & $19(7)$ & $9(3)$ & $245(90)$ & $35(13)$ & $17(6)$ & $212(80)$ & $19(7)$ & $29(11)$ & $225(82)$ \\
\hline Total & $32(10)$ & $12(4)$ & $277(86)$ & $62(20)$ & $22(7)$ & $231(73)$ & $32(10)$ & $44(14)$ & $245(76)$ \\
\hline
\end{tabular}

${ }^{*}$ Total=327 (52 girls and 275 women) who had undergone FGM.

†Data missing on two women and four girls who did not agree to genital inspection.

†Reported form missing for one girl and one woman; 10 women did not know their form. 
form of FGM could be to justify the practice by referring it to a religious term. This does not say the women are intentionally under-reporting. It could also be that the practitioner who performed the operation called it "sunna," even though she did a more extensive form. It is, however, important to note that FGM is not a religious practice as it predates the arrival of both Christianity and Islam in Africa, ${ }^{88}$ and FGM is not known in many Muslim countries. ${ }^{8}$

In a study of Somali immigrants in Sweden the respondents claimed to have stopped "circumcision." Further investigation, however, showed that though they had stopped the practice as they used to do it in their home country (infibulation, type III), instead they practised "sunna," which they defined as removing the forbidden (Haram) part. $^{29}$ This probably corresponds to clitoridectomy-WHO type I.

Most of those who promote what they call "sunna circumcision" say it entails only the removal of the prepuce of the clitoris (S A Khalid, personal communication). ${ }^{30}$ Our results, on the contrary, show a tendency to use "sunna" for all different forms of FGM. Among the 27 girls and 35 women with alleged "sunna" in our study, there was not a single case of removal of the prepuce only. This is in accordance with previous experience from Sudan $^{30}$ and Tanzania. ${ }^{23}$

\section{Classification of FGM}

Depending on what classification is used to calculate prevalence, there will be different numbers. As can be seen in table 4, among girls the prevalence of the mildest form can vary between $27 \%$ and $53 \%$ and the prevalence of the most severe form can vary between $37 \%$ and $67 \%$, depending on which classification is used. Seven of the 10 women who reported not knowing their form of FGM were verified as having type III. Studies that omit women who report "don't know" about their form may underestimate the prevalence of type III.

WHO classifies all forms that involve suturing as type III, regardless of whether the labia minora or majora have been cut. Therefore classification as type III does not indicate the extent of the mutilation that has been done. This is important, especially in investigations of FGM and complications. It is rarely pointed out that the frequency and severity of complications are a function of the extent of the operation. ${ }^{31}$

Many studies have failed to find associations between FGM and morbidity when they have used the WHO definitions. In a recent study from Sudan on the association between FGM and infertility we showed that it is important to base clinical research on the anatomical extent of FGM rather than on the WHO classification. There was a highly significant association between the anatomical extent and primary infertility, but when we used the WHO classification on the same material we found no association. ${ }^{21}$

\section{Recommendations}

In studies to estimate the prevalence of FGM and its different forms by interviews, women should be asked to explain what they mean by the different terms, including the extent of cutting. The use of visual aids might facilitate this. Clinical studies on FGM and its relation to morbidity and complications should classify forms of FGM according to the anatomical extent of FGM rather than use the WHO classification. The WHO should revise its classifications to relate the different forms more to the anatomical extent of the operation.

Abdelrahim Obeid, Mohamed A A El Sheikh, Saad M El Fadil, Staffan Bergström, Alia Satti, Hibba A Bedri, Tayseer Idris, M Sir K Hashim, Gaafar I Suliman, and Staffan Bergström participated in planning and data collection.
Contributors: SE had the original idea for the study, coordinated the planning and implementation of the study, performed most of the analyses, was responsible for writing the manuscript, and is guarantor. NE participated in planning, data collection, and analysis and interpretation of results and revised the final version of the manuscript. LA participated in the planning and continuous supervision of the study, supervised the analysis of the data and writing of the manuscript, and is guarantor.

Funding: Swedish International Development Agency, Sida/SAREC, the Regional Research Council of Northeast Skåne, Sweden, and the Department of Paediatrics, Centralsjukhuset, Kristianstad, Sweden. Competing interests: None declared.

Ethical approval: The University of Khartoum, the Children's Emergency Hospital, Khartoum, Sudan, and the Karolinska Institute, Sweden, approved the study.

1 World Health Organization. Female genital mutilation: an overview. Geneva: WHO, 1998. 2 Department of Statistics and Institute for Resource Development/Macro International. Sudan demographic and health survey 1989/1990. Columbia, MD: Department of StatisSudan demographic and health survey 1989/1990. Columbia, MD: Departm
tics and Institute for Resource Development/Macro International, 1991.

3 El Dareer AA. Epidemiology of female circumcision in the Sudan. Trop Doct 1983;13:41-5.

4 Population Council. Female circumcision in Indonesia:extent, implications and possible inter ventions to uphold women's health rights. Jakarta, Indonesia: Population Council, 2003.

Isa AR, Shuib R, Othman MS. The practice of female circumcision among Muslims in Kelantan, Malaysia. Reprod Health Matters 1999;7:137-44.

6 Johnsdotter S. Created by God: how Somalis in Swedish exile reassess the practice of female circumcision [dissertation]. Lund, Sweden: Department of Sociology, Lund University, 2002.

7 Dorkenoo E. Cutting the rose:female genital mutilation: the practice and its prevention. London: Minority Rights Publications, 1994.

8 Rahman A, Toubia N. Female genital mutilation: a guide to laws and policies worldwide. Rahman A, Toubia
London: Zed, 2000.

9 London: Zed, 2000. an offence. Do health services have a sufficient knowledge to see the problem?] Lakartidningen 2005;102:1637-43.

10 Morison LA, Dirir A, Elmi S, Warsame J, Dirir S. How experiences and attitudes relating to female circumcision vary according to age on arrival in Britain: a study among young Somalis in London. Ethn Health 2004;9:75-100.

11 Bosch X. Female genital mutilation in developed countries. Lancet 2001;358:1177-9. 12 WHO Technical Working Group. Female genital mutilation. Geneva: WHO, 1996.

13 Shandall A. Circumcision and infibulation of females. Sudan Med J 1967;5:178-212.

$14 \mathrm{El}$ Dareer A. Complications of female circumcision in the Sudan. Trop Doct 1983;13:131-3.

15 Sami IR. Female circumcision with special reference to the Sudan. Ann Trop Paediatr 1986;6:99-115.

16 Islam MM, Uddin MM. Female circumcision in Sudan: future prospects and strategies for eradication. Int Fam Plan Perspect 2001;27:71-6.

17 Verzin JA. Sequelae of female circumcision. Trop Doct 1975;5:163-9.

18 Rushwan H, Slot C, El Dareer A, Bushra N. Female circumcision in the Sudan. Prevalence, complications, attitudes and changes. Khartoum: Faculty of Medicine, University of Khartoum, 1983 .

19 Mustafa AZ. Female circumcision and infibulation in the Sudan. J Obstet Gynaecol Br Commonw 1966;73:302-6.

20 Almroth L, Bedri HA, Elmusharaf S, Satti A, Idris T, Hashim MSK, et al. Urogenital complications among girls with genital mutilation: a hospital based study in Khartoum. complications among girls with ge
Afr J Reprod Health 2005;9:127-33.

21 Almroth L, Elmusharaf S, El Hadi N, Obeid A, El Sheikh MA, Elfadil SM, et al. Primary Almroth L, Elmusharaf S, El Hadi N, Obeid A, El Sheikh MA, Elfadil SM, et al. Primary
infertility after genital mutilation in girlhood in Sudan: a case-control study. Lancet 2005;366:385-91.

22 Msuya SE, Mbizvo E, Hussain A, Sundby J, Sam NE, Stray-Pedersen B. Female genital cutting in Kilimanjaro, Tanzania: changing attitudes? Trop Med Int Health 2002;7:159-65.

23 Klouman E, Manongi R, Klepp K-I. Self-reported and observed female genital cutting in rural Tanzania: associated demographic factors, HIV and sexually transmitted infections. Trop Med Int Health 2005;10:105-15.

\section{What is already known on this topic}

Almost all studies about the prevalence and trends of female genital mutilation (FGM) have been based on women self reporting their form of FGM

How this reported form corresponds to reality is unknown

\section{What this study adds}

The reliability of reported form of FGM is low, and there is considerable under-reporting of the extent of FGM

The WHO classification fails to relate the defined forms of FGM to the severity of the operation 
24 Snow RC, Slanger TE, Okonofua FE, Oronsaye F, Wacker J. Female genital cutting in southern urban and peri-urban Nigeria: self-reported validity, social determinants an secular decline. Trop Med Int Health 2002;7:91-100.

25 Morison L, Scherf C, Ekpo G, Paine K, West B, Coleman R, et al. The long-term reproductive health consequences of female genital cutting in rural Gambia: a communitybased survey. Trop Med Int Health 2001;6:643-53.

26 Almroth L, Almroth-Berggren V, Hassanein OM, El Hadi N, Al-Said SS, Hasan SS, et l. A community based study on the change of practice of female genital mutilation in a Sudanese village. Int J Gynaecol Obstet 2001;74:179-85.

27 El Dareer A. Woman, why do you weep? Circumcision and its consequences. London: Zed, 1982.

28 Lockhat H. Female genital mutilation: treating the tears. London: Middlesex University Press, 2004.

29 Ahlberg BM, Krantz I, Lindmark G, Warsame M. "It's only a tradition”: making sense of eradication interventions and the persistence of female "circumcision" within a Swedish context. Crit Soc Policy 2004,24.50-78.

30 Toubia N. Female circumcision as a public health issue. N Engl J Med 1994;331:712-6.
31 Obermeyer CM. Female genital surgeries: the known, the unknown, and the unknowable. Med Anthropol Q 1999;13:79-106.

(Accepted 24 March 2006)

doi $10.1136 /$ bmj.38873.649074.55

Division of International Health, Karolinska Institutet, SE 17177 Stockholm, Sweden

Susan Elmusharaf medical doctor

Lars Almroth medical doctor

Department of Obstetrics and Gynaecology, Faculty of Medicine, University of Khartoum, 102 Kartoum, Sudan

Nagla Elhadi medical doctor

Correspondence to: S Elmusharaf Sozan.Elmusharaf@ki.se 